\title{
PB-SmartClass: Um Modelo Arquitetural Baseado em Projetos Colaborativos para Salas de Aula do Futuro
}

\author{
Rafael de Amorim Silva', João Gabriel G.V. Nova ${ }^{1}$, Rubem F.S. Vasconcelos ${ }^{1}$, \\ Ivo A.A.R. Calado², Kalinka R.L.J.C. Branco ${ }^{3}$, Rosana T.V. Braga ${ }^{3}$ \\ ${ }^{1}$ Instituto de Computação - Universidade Federal de Alagoas (UFAL) Caixa \\ Postal 61 - 57.300970 - Maceió - AL - Brasil \\ ${ }^{2}$ Instituto de Computação - Instituto Federal de Alagoas (IFAL) Palmeira dos \\ Índios - AL Brasil \\ ${ }^{3}$ Instituto de Ciências Matemáticas e Computação - Universidade de São Paulo \\ (USP) São Carlos - SP Brasil \\ \{rafael, jgg, rfsv\}@ic.ufal.br, ivo.calado@ifal.edu.br, \{kalinka, \\ rtvb\}@icmc.usp.br
}

\begin{abstract}
The traditional teaching method has provided a low outcome of students in the teaching-learning process, due to factors as lack of practical activities, non personalized learning, centralized teaching, among others. Therefore, it is essential to propose alternatives that engage and include the student in the learning process, implementing features from a future classroom. This paper identifies such essential features and proposes a collaborative project-based architectural model called PB-SmartClass. This model incorporates intelligent devices that work with networks of connected objects (IoT) in addition to encompass aspects such as immerse collaboration, projectdriven classes, and content personalization, providing an independent and autonomous learning and creating an optimized environment, attractive and involving for students and teachers.
\end{abstract}

Resumo. O método de ensino tradicional tem proporcionado um baixo rendimento dos alunos no processo de ensino-aprendizagem, devido a fatores como falta de atividades práticas, aprendizado não personalizado, ensino centralizado, entre outros. É necessário, portanto, propor alternativas que engajem $e$ insiram o aluno no processo de aprendizado, identificando características inerentes a uma sala de aula do futuro. Este artigo identifica as características essenciais de uma sala de aula de futuro e propõe um modelo arquitetural de automação baseada em projetos colaborativos denominada SmartClass. Tal modelo incorpora dispositivos inteligentes projetados para funcionar em redes de Internet das Coisas, visando criar um ambiente otimizado, atrativo e engajador para alunos e professores. Do lado pedagógico, será aplicado o modelo Project-Based Learning já que nosso enfoque será em aulas cujas disciplinas possam utilizar-se de projetos em que os alunos precisam de mínimo auxílio do professor e possam ter um aprendizado independente $e$ autônomo com auxílio dos módulos da Smartclass.

\section{Introdução}

Nos últimos 5 anos, a indústria e os grandes centros de pesquisa têm desenvolvido novas tecnologias de informação e comunicação para operarem no contexto de IoT (Internet das coisas). Esta rede IoT permite que inúmeros dispositivos, autônomos e 
VI Congresso Brasileiro de Informática na Educação (CBIE 2017)

Anais dos Workshops do VI Congresso Brasileiro de Informática na Educação (WCBIE 2017)

com capacidade de percepção, processamento, identificação e localização, compartilhem informações sobre seus estados e permita inferir novos conhecimentos baseados em suas interações [1]. Exemplos incluem dispositivos que captam inúmeras informações do ambiente em plantas de fábricas, veículos que se comunicam para alertar possíveis problemas em uma dada região, eletrodomésticos que compartilham informação sobre situações específicas em uma casa inteligente, monitoramento de dados biológicos dos pacientes em hospitais, identificação e localização de objetos de aprendizado em salas de aula, etc.

No contexto educacional, reunir tais dispositivos e fazê-los operar em um ambiente sendo gerenciados por um sistema inteligente torna-se um grande desafio, já que salas de aula devem ser preparadas e automatizadas apropriadamente. Além do fato de termos que automatizar o ambiente, é necessário a investigação e escolha de uma abordagem mais eficiente de ensino e aprendizagem, aumentando o engajamento dos alunos em sala e permitindo uma maior utilização dos recursos computacionais imersos na rede IoT. A abordagem tradicional de ensino em uma sala de aula limita o aprendizado do aluno, já que não é personalizado [2]. Neste caso, é fundamental que haja um sistema que trate um aluno de forma individualizada, como um indivíduo com características únicas, com deficiências educacionais a serem tratadas de um jeito específico.

Em virtude desta problemática, este artigo investiga e propõe um modelo arquitetural de automação com o foco na criação de uma sala de aula que utiliza recursos computacionais inteligentes. A criação de tal sala torna mais proveitosa a experiência do ensino, pois, agora, o usuário poderá aprender um determinado assunto de acordo com suas próprias limitações e também sob a perspectiva de diversos educadores, utilizando específicas tecnologias de informação e comunicação. $O$ propósito deste modelo é proporcionar ao aluno uma sala de aula que ofereça uma experiência de aprendizado maior, onde ele possa ter acesso rápido a conteúdos de diferentes fontes, incentivando seu engajamento durante as aulas.

Este artigo é estruturado da seguinte maneira. Na Seção 2, a fundamentação teórica necessária para a compreensão das características inerentes a uma sala de aula de futuro é descrita. Além disso, os quatro componentes principais do modelo SmartClass são apresentados. Na Seção 3, a problemática é apresentada e discutida. A Seção 4 apresenta a proposta deste artigo, descrevendo o modelo arquitetural baseado em projetos colaborativos, enfatizando-se a modelagem computacional. A Seção 5 apresenta um estudo de caso de como funcionaria tal modelo arquitetural em um ambiente real de sala de aula. A Seção 6 apresenta as considerações finais do artigo.

\section{Trabalhos Relacionados}

As salas de aula do futuro são um conceito recente do modelo ideal de sala de aula para as próximas gerações de estudantes, sendo um tema ativo e largamente pesquisado nos últimos anos. Não há ainda como definir quais componentes tecnológicos e educacionais formarão o conceito destas salas. Entretanto, alguns fatores deverão fazer parte deste conceito [3]: (i) a integração total da tecnologia digital, substituindo ferramentas atuais como o papel; (ii) mudança na forma de se transmitir o conhecimento, dando espaço para abordagens como micro learning, active learning, 
VI Congresso Brasileiro de Informática na Educação (CBIE 2017)

Anais dos Workshops do VI Congresso Brasileiro de Informática na Educação (WCBIE 2017)

project-based learning, entre outras; (iii) gamificação das aulas, transformando estas em um aprendizado mais dinâmico, interativo e divertido; (iv) Conectividade, permitindo que o conhecimento não seja apenas repassado em salas físicas, mas sim difundido em redes sociais virtuais ou em colaboração com outras instituições; (v) transparência, estimulando a cooperação entre alunos, professores, pais e instituições; (vi) o autodidatismo, definindo a própria busca do aluno para formar o seu conhecimento; e (vii) lugar, ultrapassando as barreiras físicas das salas de aula e estimulando a ubiquidade do aprendizado.

Nos últimos anos, percebe-se um esforço considerável no estudo e aplicação de novos métodos, técnicas e abordagens pedagógicas para reduzir o desinteresse e a desmotivação dos alunos em salas de aula que aplicam o modelo tradicional de ensino. Um dos métodos seria a utilização de ambientes virtuais de aprendizagem, proporcionando a transição das salas de aula baseadas em espaços físicos para salas de aula virtuais. Os autores em [4][5] discutem tal tópico em detalhes. Enquanto que o autor [4] elabora uma ferramenta com características aperfeiçoadas para que palestrantes e aprendizes possam colaborativamente interagir com participantes em uma sala de aula virtual baseada na Web, os autores em [5] investigam uma sala de aula virtual aplicável para pessoas com deficiências físicas, especificamente surdas, elaborando um aprendizado através de um método bilingue. Ambos os métodos permitem inúmeras facilidades no aprendizado de usuários comuns ou deficientes.

Os autores em [6][7][8][9] defendem o uso de dispositivos móveis como a principal ferramenta de aprendizado nas salas de aula do futuro. Os autores em [6] investiga os desafios e oportunidades em se aplicar dispositivos móveis como ferramenta do processo de ensino-aprendizagem no ensino básico norte americano. Tal estudo investiga aspectos como mudanças nas atitudes dos professores, crenças e percepções sobre o ensino e aprendizado utilizando tais tecnologias. Os autores em [7] desenvolvem um sistema de aprendizado ubíquo baseado em simulações computacionais chamado EDISON, específico para apoiar usuários no aprendizado de dinâmica de fluídos computacionais. Os autores em [8] investiga o nível de inclusão destes dispositivos móveis em salas de aula universitárias, além de analisar informações sobre a percepção dos estudantes nos anos finais de mestrado de uma respectiva universidade. Tais estudos citados acima demonstram a importância deste tipo de aprendizado na aplicação das aulas atuais e futuras. Os autores em [9] defedem a ideia de um aprendizado híbrido, conectando o aprendizado online com sessões presenciais. Tais autores investigam os fatores norteantes da adoção de mobile learning por autodidatas. Esta investigação sugere que a leitura e suporte para pessoas autodidatas em sistemas de ensino a distância híbrido ainda seja carente de pesquisas.

Por outro lado, alguns autores [10][11] têm pesquisado sobre a eficiência do aprendizado ativo em contextos educacionais. Os autores em [10] desenvolvem um estudo para compreender a aplicação do ensino invertido convencional para contribuir com o ensino em sala de aula, identificando fatores chave e a efetividade das estratégias de aprendizado e ensino para desenvolver um modelo de ensino invertido mais aprimorado. Já os autores em [11] investigam a eficiência de interfaces de usuários tangíveis, responsáveis por preparar estudantes para o aprendizado em salas de aula do futuro e permitindo que grupos de estudantes colaborem e descubram conceitos específicos de probabilidade. 
Embora as salas de aula do futuro projetem ambientes mais ativos, colaborativos e cooperativos, o processo de ensino-aprendizagem aplicado nas escolas e universidades do Brasil ainda não se beneficia da experiência educacional de outras instituições e da prática do aprendizado ativo apropriadamente. Dentre os problemas existentes nas salas de aula tradicionais, destacam-se [12][13]: (i) Ensino subjetivo - O ensino nas escolas e faculdades é subjetivo, pois cada grupo de professores ensinam uma disciplina da sua forma, dificultando o alinhamento necessário entre os estudantes e os trabalhos da literatura; (ii) Processo de Análise Demorada - Experimentos científicos podem ser analisados, observados em tempo real, contribuindo com o estudo em questão; (iii) Imaturidade dos Usuários - Utilizar a abordagem de projetos para o amadurecimento dos usuários em questão; (iv) Gestão Ineficiente em Sala de Aula - Aumentar a eficiência da Gestão em Sala de Aula e fora para que, através dessa gestão, haja um engajamento maior de aluno e professor. Portanto, as salas de aula atuais e futuras ainda não levam em conta um aprendizado baseado em projetos que integre todos os aspectos citados nos trabalhos anteriores, como colaboração, personalização e automação.

\section{Proposta}

Levando-se em conta os problemas citados na seção anterior, este artigo propõe a criação de uma sala de aula que utiliza recursos computacionais inteligentes para tornar a experiência de ensino mais rica. Tal ambiente permitirá que o aluno aprenda um determinado assunto sob a perspectiva de diversos educadores, utilizando específicas tecnologias de informação e de comunicação, além de aprender junto com suas limitações. Esta sala de aula permitirá: (i) um ensino alinhado com diversas instituições de referência, permitindo a obtenção de um conteúdo mais atualizado e global; (ii) dados reais e atualizados de experiências em campo, além da comunicação entre os atores envolvidos nesta experiência, o que possibilita uma colaboração mais imersiva; (iii) a experiência e participação em projetos de sala de aula, utilizando recursos que permitam um usuário a programar suas participações nas atividades destes projetos; e (iv) Engajamento de alunos e professores, aumentando a produtividade destes através de uma gestão eficiente.

\subsection{Principais Componentes}

O conceito de Sala de Aula de Futuro definido pelos autores deste artigo baseia-se na ideia de uma plataforma interativa online conectada a uma gama de dispositivos IoT, tanto da instituição e professores quanto dos alunos, promovendo um relacionamento entre ambos. Nesta nova estratégia, o professor deverá disponibilizar o conhecimento necessário para que seus alunos possam desenvolver os projetos aplicados em sala de aula, de forma autônoma. Para que tal estratégia seja realizável, define-se quatro pilares do conceito SmartClass: (i) Aulas dirigidas a Projetos; (ii) Personalização de Conteúdo; (iii) Colaboração Imersiva; e (iv) Ambientes envolventes.

Aulas dirigidas a Projetos - Com o evidente nível de desmotivação presente nos alunos em aulas expositivas e meramente teóricas, a ideia é que os estudantes tenham a oportunidade de aprender o conteúdo das disciplinas por meio de protótipos e projetos das mesmas, tornando o aprendizado mais empírico e portanto, consistente [14]. Para isso, o professor deve instruí-los apenas o necessário para que os alunos 
tenham um ponto de partida para fazerem estudos independentes ou desenvolverem seus projetos, aprendendo na prática os conteúdos necessários para suas disciplinas. Não limitando a interação entre alunos, o modelo SmartClass visa atingir também outras instituições, levando a criação de projetos inter-institucionais e troca de informações entre alunos e professores das mesmas, gerando conexões futuras e maiores experiências por meio de um projeto disciplinar.

Personalização de Conteúdo - Visando um aprendizado dos alunos de forma independente, é necessária a criação de ferramentas que auxiliem a aquisição de conhecimento dos estudantes a partir dos dados inferidos com a plataforma [2]. A ideia é criar sistemas que avaliem a produtividade e o desenvolvimento dos alunos a ponto de poder indicar exercícios, materiais e projetos que possam otimizar sua aprendizagem. Sendo assim, as ferramentas seriam baseadas em um sistema de personalização e recomendação de conteúdos para os alunos, facilitando a aprendizagem de alunos que não estivessem no mesmo ritmo das aulas e direcionando o ensino para os pontos fracos e que ainda precisam ser explorados pelo aluno.

Colaboração Imersiva - um dos maiores desafios de uma sala de aula tradicional é associar aulas teóricas com situações reais onde tais teorias poderiam ser aplicadas. A colaboração imersiva surge como uma alternativa para que alunos tenham acesso a dados e informações providos de experiências reais para desenvolver seus conhecimentos em determinados assuntos e auxiliá-los em seus projetos. Busca-se a conectividade entre alunos, professores e profissionais em campo, fazendo com que os alunos tenham acesso a dados de profissionais que utilizam-se dos conhecimentos que estão sendo desenvolvidos em sala de aula na prática. Tal nível de colaboração profunda pode ser exemplificada durante uma aula de biologia marinha, onde os alunos teriam contato com um mergulhador em campo por videoconferência, realizando perguntas e tirando dúvidas sobre um assunto discutido em sala de aula. Outro exemplo inclui alunos de Agronomia coletando informações de sensores espalhados em uma dada plantação, observando aspectos como crescimento das plantas e qualidade de solo neste ambiente. Portanto, esta colaboração permite que os alunos aprendam de forma interativa, criando vínculos e conexões com especialistas de áreas que podem ser de seus interesses.

Ambientes Envolventes - Tais ambientes seriam utilizados nas aulas expositivas ou sessões de projeto, dotando de um ambiente tecnológico envolvente que ajudasse a engajar os estudantes no aprendizado. Tais ambientes são caracterizados por projeções multimídias $360^{\circ}$ (i.e. em todas as paredes de uma dada sala de aula), aumentando a sensação de imersão em dados e informações para o aprendizado dos alunos. Além disso, os estudantes estariam dispostos em mesas circulares para grupos, não mais em cadeiras individuais. Cada mesa circular conteria aparelhos com os quais os estudantes poderiam se conectar com os projetores, criando assim uma experiência de sala de aula que não estaria apenas nas mãos dos tutores, mas sim de todos os envolvidos.

\subsection{Modelo Arquitetural}

O modelo arquitetural proposto neste artigo utiliza os pilares citados na Seção 3 e incorpora sete módulos para a formação de um sistema integrador educacional. A conexão entre os módulos é ilustrada na Figura 1, sendo cada módulo descrito a seguir. 


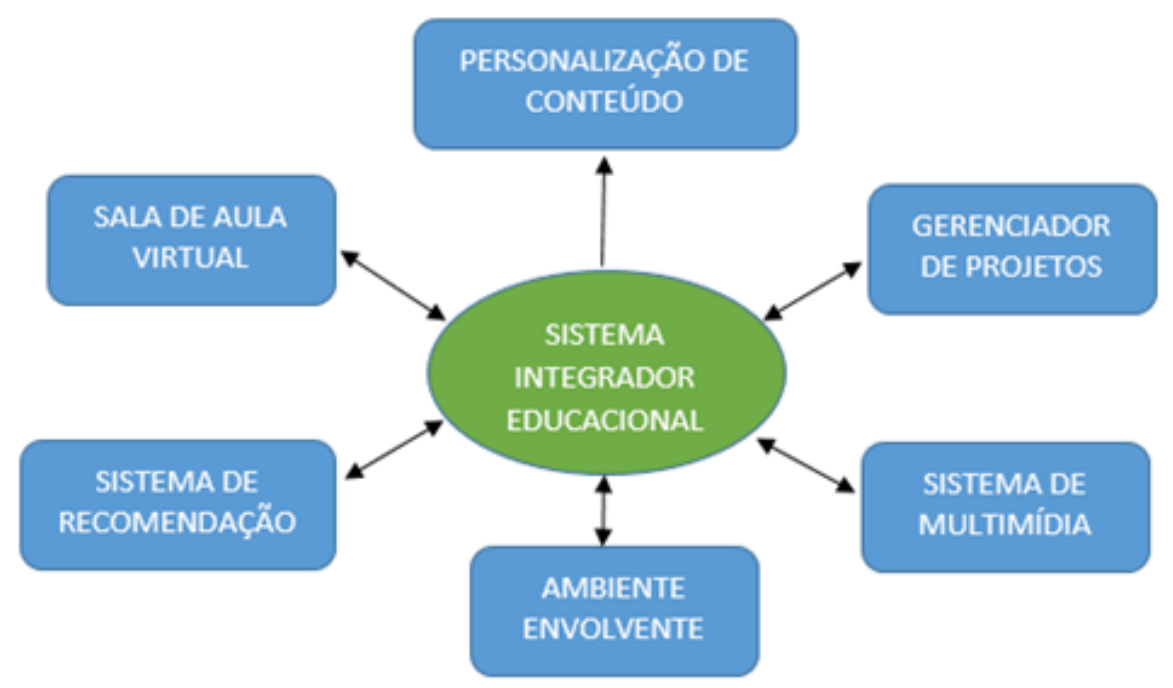

Figura 1: Visualização dos módulos da Smartclass

O Sistema de Integração Educacional (SIE) funciona como um mediador entre todos os outros módulos e é ele quem detém as informações dos usuários e componentes do sistema. Todos os aparelhos quando necessitarem de informações ou demandas diretamente de outros dos módulos da Smartclass precisarão fazer uma requisição para o SIE que irá validar o pedido e alcançará o módulo necessário pedindo a informação e a retornando para o módulo requisitante. Abrigando também as informações e modelos dos usuários, o SIE tem uma forte ligação com os Sistemas de Personalização e Recomendação de Conteúdo, já que utilizando-se de suas informações ele pode se conectar a estes sistemas e gerar os dados necessários para a personalização e recomendação de materiais e atividades para os alunos.

A Sala de Aula Virtual (SAV) é um módulo que consiste de uma plataforma onde alunos e professores podem se conectar para compartilhar material e estudar livremente ou por meio de sessões e aulas. A janela de uma SAV conterá um canal de vídeo e áudio, além da possibilidade de compartilhamento de telas e arquivos de multimídia. Essa ferramenta poderia ser utilizada juntamente com a ideia de que alunos de diferentes instituições poderiam trabalhar de maneira cooperativa para desenvolver projetos disciplinares, ou seja, estudantes podem criar salas de estudo para compartilharem seus arquivos e ideias facilitando o trabalho em grupo a distância. Além de tudo, as SAVs iriam analisar o engajamento de alunos e suas conexões, enviando essas informações para os professores se requisitado para auxiliá-lo nas avaliações dos mesmos. Outro conceito que pode contemplado pelas SAVs é o de n-teachers. Criado por nós, este conceito explica que com o advento da Smartclass alunos não precisariam apenas ter acesso a um tutor em uma sala de aula, as instituições conectadas entre si que estiverem disponibilizando as mesmas disciplinas podem compartilhá-las criando assim uma "sala de aula universal”, onde alunos de uma instituição podem ter contato com tutores de outra e trabalhar juntos com alunos da mesma.

O gerenciador de Projetos (GP) seria o responsável por organizar os grupos e as instâncias de projetos criadas pelos tutores para os alunos. Este gerenciador também poderia selecionar estudantes para compor um grupo, equilibrando suas forças e fraquezas para gerar equipes em que a experiência pessoal de cada um seja importante e que todos pudessem adquirir mais conhecimento a partir da atividade. O GP se 
comunicaria com o SIE que acessaria os dados sobre os alunos e geraria os grupos para o tutor, podendo ele aceitar a sugestão, editá-la ou apenas criar os grupos manualmente como preferir. Além disso, os alunos colocariam seus avanços na plataforma do GP onde este analisá-los-ia de acordo com parâmetros que o tutor definiria quando criado um projeto. Sendo assim, o GP seria uma ferramenta organizacional indispensável para os projetos em nossa Smartclass, ainda mais levando em conta a possibilidade da criação de grupos compostos por estudantes de diferentes instituições.

O Sistema de Recomendação (SR) seria um módulo fortemente acoplado ao SIE que utiliza-se dos dados neste para gerar modelos de usuários e recomendar atividades, materiais e disciplinas para os alunos de acordo com suas fraquezas e forças, sendo estas determinadas pelas atividades que eles efetuam nas plataformas virtuais da Smartclass, como na SAV. A importância desse módulo vem da necessidade de otimização do tempo tanto do aluno, quando efetuando suas atividades e estudos na plataforma, quanto do professor que pode receber auxílio desse módulo para selecionar alunos no GP ou até mesmo atividades e projetos de acordo com uma visão geral das proficiências de sua turma.

O Sistema Controlador de Multimídia (SCM) é um dos mais básicos e mecânicos da Smartclass, é nele que é delimitado o controle dos aparelhos da sala de aula como projetores, lousas digitais e conexão entre aparelhos pessoais dos alunos. Este sistema definirá as permissões de usuários para utilização dos aparelhos da instituição e fará a ponte entre o dispositivo do usuário com o aparelho a ser utilizado, comumente por meio da tecnologia Bluetooth. Um aluno com as permissões necessárias poderia utilizar seu aparelho pessoal acessando a plataforma do SCM para controlar um projetor para efetuar uma apresentação rápida ou tirar uma dúvida mostrando alguns fatos durante a própria aula, levando em conta que o tutor estaria permitindo o acesso dos alunos aos projetores naquele momento. Novamente, o SCM vem como um otimizador de tempo, já que o mais notável atualmente é a perda de tempo que temos em uma sala de aula convencional.

O Sistema de Personalização de Conteúdo (SPC) é um complemento do SR porém, neste caso, o SPC age sem que o usuário perceba. Enquanto o aluno está utilizando a plataforma realizando suas atividades e estudos, o SPC está analisando seus erros e acertos e automaticamente mudando as questões de atividades de uma determinada disciplina, facilitando ou dificultando as mesmas para melhor aproveitamento do aluno. Além disso, em momentos de estudo, o SPC disponibiliza informações que parecem ser mais válidas para o usuário de acordo com seu perfil gerado pelo SIE, por exemplo: Em uma sessão de estudo de Cálculo na plataforma, se o aluno já está bem familiarizado com assuntos sobre funções de diversos tipos (análise esta vindo de atividades desenvolvidas na plataforma) o SPC automaticamente direciona o aluno para o próximo assunto pertinente de Cálculo, por exemplo, limites e derivadas.

Os Ambientes envolventes (AE) propiciam ambientes mais engajadores e estimulantes para o aprendizado. Nas salas de aula atuais não temos muito para engajar o aluno nas atividades que não sejam derivados da própria habilidade de lecionar do professor. A ideia da criação de um AE é que o aluno se sinta mais engajado em aprender o conteúdo e praticá-lo em sala de aula. Na nossa perspectiva, uma AE deveria conter mesas redondas onde alunos pudessem sentar juntos e em grupos de discussão. Essas mesas deveriam conter pico-células Bluetooth com a capacidade de conectar tanto 
os aparelhos pessoais dos estudantes (tablets e smartphones) entre si, quanto estes com algum outro aparelho de multimídia da sala (aparelhos de som ou projetores). A tecnologia deve ser englobada no ambiente escolar para torná-lo mais ativo e motivador, com nossas ideias uma sala de aula poderia melhorar a discussão entre os alunos e novamente otimizar a produção de sala de aula, tendo em vista que os alunos poderiam trocar arquivos e informações muito mais rápido estando conectados em rede e fazer apresentações e tirar dúvidas de maneira mais dinâmica e expressiva com a utilização de projetores durante a aula.

\section{Cenários de Aplicação}

Para uma definitiva sala de aula futurística seriam necessárias diversas aplicações em todos os âmbitos do ensino, utilizando-se de conceitos de computação pervasiva, redes de computadores, inteligência artificial, computação multimídia e softwares de personalização [7]. Pensando nesta problemática, utilizaremos como estudo de caso um dos micromódulos trabalhados recentemente, sendo este um sistema tutor inteligente que utiliza tecnologia vestível para otimizar o aprendizado do aluno em aulas de música.

\subsection{Contextualização}

Esta aplicação baseia-se na ideia de um sistema pervasivo sem necessitar que professores auxiliem o aluno em seu aprendizado, dando a ele a possibilidade de aprender de acordo com seus próprios padrões. Isto é, o estudante estaria livre para estudar e praticar aonde ele quisesse, não se prendendo a um ambiente de sala de aula. Neste caso, o aluno entrará no sistema e poderá usar seu registro para acessar remotamente de onde estiver, pois muitas vezes a infraestrutura do ambiente não suporta determinadas atividades. Esta aplicação possuirá um menu no qual será possível a escolha de quatro modos diferentes de interações. O primeiro modo de interação é chamado de play-along, onde o usuário poderá tocar acompanhando a música que será escolhida por ele. O modo free style, onde o usuário tocará de maneira livre. A diferença está nos outros modos, que são o tutor e evaluative, que utilizarão o histórico do de aprendizagem para sugerir novas músicas e avaliar o desempenho do aluno. Os diagramas de atividades a seguir demonstram de maneira mais específica $o$ funcionamento de alguns dos módulos do sistema em questão, iniciando pelo Sistema de Avaliação, que seria o resumo das atividades do modo evaluative visto pelo lado do sistema, na Figura 2.

Este sistema avalia a performance dos alunos dividindo a música em fragmentos de até 20 segundos, avaliando sua precisão separadamente e depois unificando os resultados, gerando assim feedback em partes individuais da música tocada e possibilitando treino nos fragmentos que o aluno sofrer mais dificuldades. Na Figura 3 apresentamos um pouco da ideia do Sistema de Tutoria com seu diagrama de atividades. Este seria o sistema que apoiaria o modo evaluative, em função de possibilitar que os alunos treinem suas habilidades a partir de exercícios propostos e fragmentos de músicas das quais tiveram dificuldades. Todos os dados de performance dos alunos são guardados e analisados pelo sistema para gerar melhores exercícios e retirar a prioridade de treinos que já não são tão necessários. 
VI Congresso Brasileiro de Informática na Educação (CBIE 2017)

Anais dos Workshops do VI Congresso Brasileiro de Informática na Educação (WCBIE 2017)

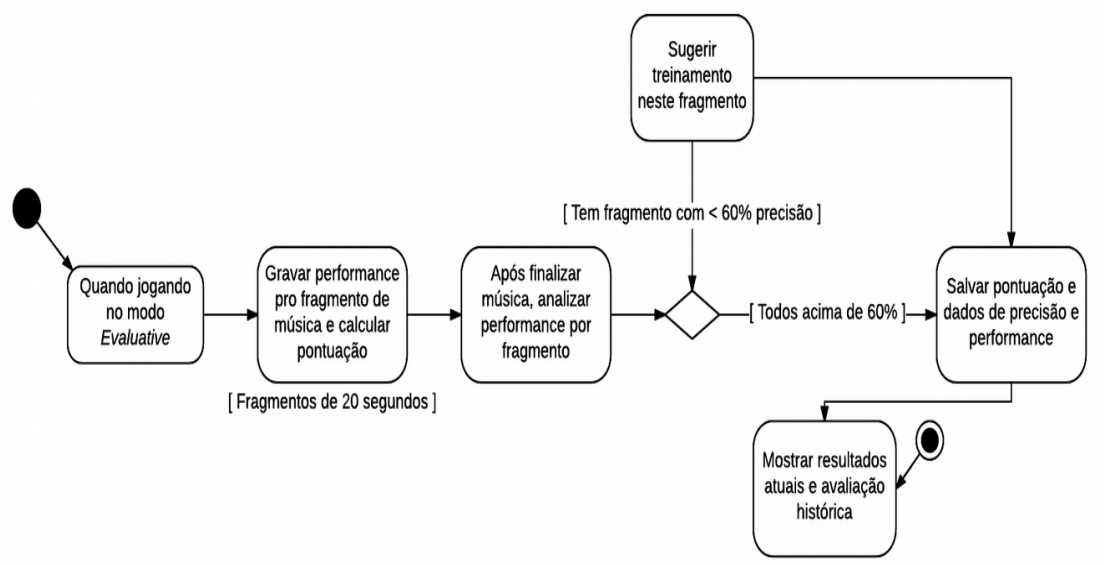

[Contém Pontuação, Precisã̃o Média, Gráfico de Precisão Temporal e Avaliação Histórica]

Figura 2: Diagrama de Atividades do Sistema de Avaliação

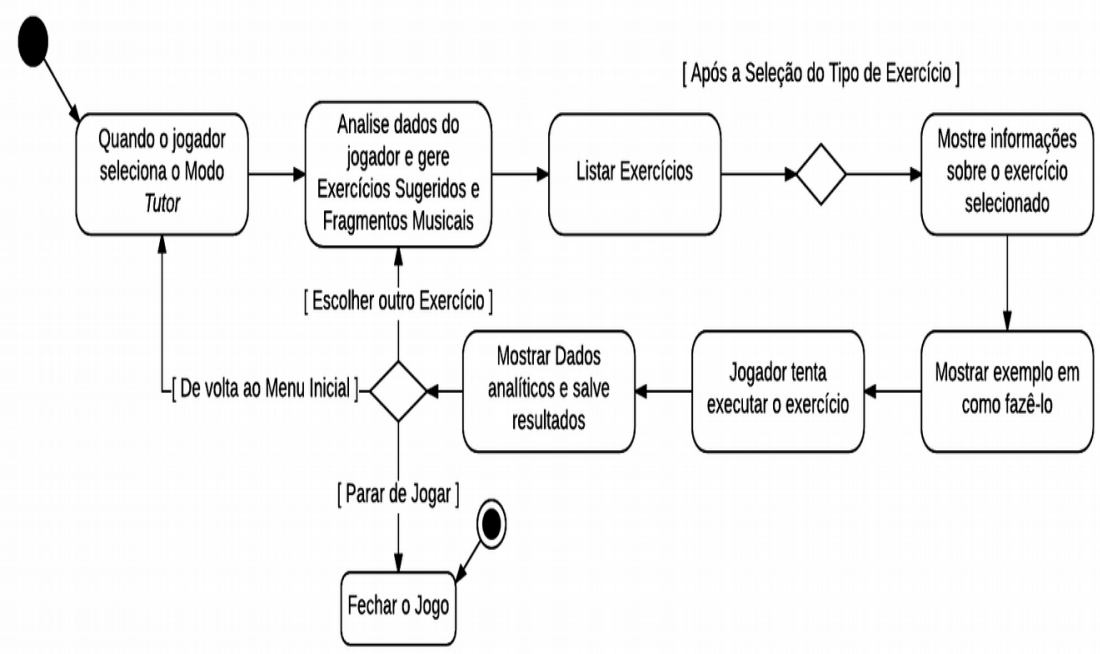

Figura 3: Diagrama de Atividades do Sistema de Tutoria

Tendo em vista agora o lado físico da aplicação, estes são os materiais utilizados para o correto funcionamento do sistema: (i) luva eletrônica com sensores de movimento; (ii) teclado controlador (iii) óculos de realidade aumentada; (iv) headphones; (v) smartphones. O item (i) corresponde a uma luva do tipo sensitive fingertips, responsável por optar a movimentação da mão de um usuário e transmitir os dados via tecnologia Wi-Fi. Tal luva deve conter um acelerômetro que além de definir informações sobre a movimentação, também deve captar pressão dos dedos e altura das mãos. O item (ii) refere-se a um teclado controlador que servirá para identificar a sequência de teclas pressionadas pelo usuário durante o processo de avaliação do sistema. O item (iii) corresponde a um óculos de realidade aumentada que será associado a um dispositivo smartphone para visualizar as telas do jogo enquanto se tem visão do teclado. O item (iv) corresponde a um headphone que processará o som do sistema utilizando a tecnologia bluetooth. O item (v) corresponde ao uso de smartphones que carregará a aplicação proposta. 
VI Congresso Brasileiro de Informática na Educação (CBIE 2017)

Anais dos Workshops do VI Congresso Brasileiro de Informática na Educação (WCBIE 2017)

\subsection{Aplicando PB-SmartClass para o Aprendizado de Música}

Suponha que um aluno deseja participar das aulas de teclado utilizando-se do micromódulo para auxílio de aprendizagem musical do Smartclass. Ele então deve se cadastrar no sistema e então preparar todos seus dispositivos (teclado controlador, óculos, fones e smartphone) conectando-se a aplicação. Em seguida, o aluno será lançado numa tela de menu, tendo as opções de play-along, tutor, evaluative e free style. $\mathrm{O}$ aluno então resolve tocar uma música no modo evaluative para poder obter feedback e melhorar suas habilidades. Após escolher uma música na lista apresentada pelo aplicativo, o aluno inicia o toque da mesma, em seus óculos o aluno consegue ver as notas que deveriam ser tocadas surgindo como vários jogos de música atuais.

Após terminada a música, o sistema avaliará a performance do aluno utilizandose de um algoritmo de matching baseado em Lógica Fuzzy para comparar o que deveria ter sido tocado e o que o aluno tocou, gerando assim dados sobre sua precisão. Enfim, quando analisados os dados, o sistema disponibilizará para o aluno sua porcentagem de acertos e um gráfico apresentando em que momentos da música sua performance foi melhor ou pior. Tendo em vista os dados coletados, o sistema apresentará opções de treinamentos para que o aluno melhore as habilidades necessárias para tocar aquela música específica, sendo estas atividades exercícios básicos ou até mesmo a faixa de música que o aluno teve dificuldades para ser tocada. Tudo isso será adicionado na lista de exercícios do modo tutor, onde o aluno poderá ir a qualquer momento praticar faixas com dificuldade entre outras atividades. Com certo tempo de prática, o aluno pode acessar um histórico gráfico de suas performances, acompanhando seu desempenho ao passar do tempo.

\subsection{Impactos Pedagógicos}

Com características muito similares a jogos, este sistema trará uma atividade gamificada para auxiliar o desempenho de alunos no aprendizado de piano. Apesar da ideia do sistema ser a da criação de independência do aluno de um professor, nós sabemos, citando [14], que esse tipo de sistema deve ser inserido em um contexto e uma situação de ensino baseados em uma metodologia que oriente o processo. No nosso caso, esta metodologia seria o PBL, que para [15] é a melhor maneira de abordar o planejamento pedagógico de sistemas tutores. Levando em consideração os benefícios de jogos educacionais ou sistemas tutores gamificados como o que propomos, podemos destacar algumas vantagens apresentadas por [15]: (i) Motivação - Jogos tem um efeito de motivação e engajamento nas pessoas que os utilizam, devido a apresentação de desafios, da curiosidade do usuário, da fantasia empregada nos mesmos e da interação com o próprio jogo. Os desafios sempre precisam ser superados, gerando motivação e vontade de superação, podendo até acarretar em recuperação do ânimo para o estudo de determinada disciplina; (ii) Aprendizagem Facilitada - Jogos digitais tem a capacidade de representar vários cenários de aprendizagem visualmente, facilitando a assimilação do conteúdo. Além disso, colocam o aluno no papel de tomador de decisão e não apenas de ouvinte passivo, expondo o mesmo a vários níveis de desafios, possibilitando uma aprendizagem baseada em tentativa e erro. (iii) Desenvolvimento de Habilidades Motoras - Vários tipos de jogos desenvolvem as habilidades motoras, principalmente correlacionadas com os músculos das mãos e olhos. Nosso aplicativo não seria 
VI Congresso Brasileiro de Informática na Educação (CBIE 2017)

Anais dos Workshops do VI Congresso Brasileiro de Informática na Educação (WCBIE 2017)

diferente, ajudando os alunos a desenvolverem sua coordenação motora e habilidades espaciais.

\section{Conclusão}

Em suma, nosso grupo desenvolveu uma arquitetura para uma sala de aula futurística, Smartclass, com enfoque na otimização do tempo, aumento do engajamento dos alunos, facilidade de gerenciamento do espaço físico e dos usuários do sistema. Os módulos em separado ainda estão em desenvolvimento porém o que viemos apresentar neste artigo é a idealização de como estes mesmos devem interagir entre si tentando gerar a experiência almejada para um nova sala de aula, além da apresentação sobre o micromódulo de tutoria de música. Com um enfoque em melhorar a experiência dos alunos e professores na sala de aula convencional por meio do uso da tecnologia em vários dos âmbitos do ensino, além da aplicação das técnicas de Problem-based Learning, concluímos que nossa visão de uma Smartclass tem potencial para alcançar as metas almejadas caso implementado e refinado.

\section{Referências}

[1] Al-fuqaha, A. and Guizani, M. and Mohammadi, M. and Aledhari, M. and Ayyash, M. (2015). Internet of Things: A Survey on Enabling Technologies, Protocols, and Applications, in IEEE Communications Surveys \& Tutorials, vol. 17, no. 4, pages 23472376, IEEE.

[2] Nuraini, C. and Mohd, K. and Shahbodin, C.K. (2015). Personalized Learning Environment (PLE) Integration in the 21st Century Classroom, In International Journal of Computer Information Systems and Industrial Management Applications, ISSN 2150-7988 Volume 7, pages 014-021.

[3] WPENSAR BLOG. 7 mudanças necessárias para construir as salas de aula do

futuro. Disponível em: <https://blog.wpensar.com.br/comunicacao-escolar/7-mudacasnecessarias-para-construir-as-salas-de-aula-do-futuro/> Acesso em: 15 de setembro de 2017.

[4] Ketmaneechairat, H. and Seewungkum, D. and Caspar, M. (2013) "Web-based virtual classroom system model based on asynchronous and synchronous learning", In: Second International Conference on Future Generation Communication Technologies, Pages: 108 - 113, IEEE Conference Publications

[5] Chowdhuri, D. and Parel, N. and Maity, A. (2012) "Virtual classroom for deaf people”, In: IEEE International Conference on Engineering Education: Innovative Practices and Future Trends, Pages: 1 - 3, IEEE Conference Publications

[6] Lin, M.F. and Fulford, C.P. and Ho, C.P. and Iyoda, R. and Ackerman, L.K. (2012) "Possibilities and Challenges in Mobile Learning for K-12 Teachers: A Pilot Retrospective Survey Study”, In: IEEE Seventh International Conference on Wireless, Mobile and Ubiquitous Technology in Education, Pages 132 - 136.

[7] Lee, J.R. and Jung, Y.J. and Park, S.R. and Yu, J. and Jin, D.S. and Cho, K. (2012) "A Ubiquitous Smart Learning Platform for the 21st Smart Learners in an Advanced Science and Engineering Education”, In: 15th International Conference on NetworkBased Information Systems, Pages: 733 - 738.

[8] Blanca García-Riaza, B. and Iglesias-Rodríguez, A. (2016) "Mobile devices as learning tools: present and prospective use by future professionals of education”, In: 
VI Congresso Brasileiro de Informática na Educação (CBIE 2017)

Anais dos Workshops do VI Congresso Brasileiro de Informática na Educação (WCBIE 2017)

Proceedings of the Fourth International Conference on Technological Ecosystems for Enhancing Multiculturality, Publisher: ACM, 2016.

[9] Wan Abdul Rahim Wan Mohd Isa, W.A.R.W.M. and Lokman, A.M. and Mustapa, M.N. and Sah, I.N.M. and Hamdan, A.R. and Luaran, J.E. (2015) "Exploring the Adoption of Blended Learning: Case of Mobile Learning”, In: 3rd International Conference on Artificial Intelligence, Modelling and Simulation (AIMS), Pages: 359 364, IEEE Conference Publications.

[10] Kang, Y. and Shih, C. and Chen, L. (2016) "Construction and application of flipped instruction model”, In: International Conference on Applied System Innovation (ICASI), Pages: 1 - 3, IEEE Conference Publications

[11] Schneider, B. and Blikstein, P. (2016). Flipping the Flipped Classroom: A Study of the Effectiveness of Video Lectures Versus Constructivist Exploration Using Tangible User Interfaces, In: IEEE Transactions on Learning Technologies, Volume: 9, Issue: 1, Pages: 5 - 17 .

[12] Antona, M. and Leonidis, A. and Korozi, M. and Ntoa, S. (2011) “A StudentCentric Intelligent Classroom", In: International Joint Conference on Ambient Intelligence.

[13] Aslan, S. and Reigeluth, C. M. (2011) "A Trip to the Past and Future of Educational Computing: Understanding its Evolution”, In: Contemporary Educational Technology, pages 1-17.

[14] Koh, J. H. L. and Herring, S. C. and Hew, K. F. (2010) Project-Based Learning and Student Knowledge Construction During Asynchronous Online Discussion. In: Internet and Higher Education, Elsevier.

[15] Seo, S. and Kim, E. (2015). Development of Collaborative Problem-Based Learning Model based on Smart Education, In: Advanced Science and Technology Letters, Vol.115, pages 79-86. 